\title{
A contribuição dos genes BRCA na predisposição her editária ao câncer de mama
}

BRCA Genes Contribution in the her editary predisposition for breast cancer

Luis Cláudio Belo Amendola, ${ }^{1}$ Roberto Vieira ${ }^{2}$

\section{Resumo}

A proximadamente $20 \%$ dos casos de câncer de mama familiar estão associados a um dos genes de susceptibilidade hereditária para câncer de mama e ovário, BRCA1 e BRCA2. Recentes trabalhos têm demonstrado o mecanismo de ação destes genes com funções estabelecidas na manutenção da integridade do genoma e no controle da recombinação homóloga. A história familiar, a bilateralidade, o acometimento precoce e achados histopatológicos específicos são fatores sugestivos da presença de mutações nestes genes Esta revisão sumariza alguns destes conhecimentos, na tentativa de colocá-los no contexto atual das funções destes genes.

Palavras-chave: N eoplasias mamárias; Genética; Genes BRCA.

\begin{abstract}
A pproximately $20 \%$ of the cases related to familiar breast cancer are associated to one gene of hereditary susceptibility for breast and ovarian cancer, BRCA1 and BRCA2. Recent works have demonstrated the mechanism of action of these genes, with functions well established for maintaining the genome integrity and for controlling homologates recombination. Familiar history, bilaterality, precocious diseases, as well as specific histopathologic results are indicative factors of the presence of mutation in these genes. This literature review summarizes some of this knowledge, trying to understand them in the current functional context of these genes.
\end{abstract}

Key words Breast neoplasms; Genetic; BRCA genes.

\footnotetext{
${ }_{1}^{1}$ M estre em Saúde da Criança e da M ulher - Instituto Fernandes Figueira - FIOCRUZ, Coordenador Administrativo do Projeto Câncer de M ama e Genética - FIOCRUZ, Especialista em M astologia - SBM, Especialista em Ginecologia e O bstetrícia

2 M estre e D outor - Instituto Fernandes Figueira - FIO CRUZ, Pesquisador e Professor da Pós-G raduação do IFF, Chefe do Serviço de M astologia do IFF

- FIOCRUZ Coordenador do Projeto Câncer de M ama e Genética

Endereço para correspondência: R. do Catete, 311/1.104 - 22220-001 - Rio de Janeiro - RJ
} 


\section{INTRO DUÇÃO}

N o Brasil, o câncer de mama é a neoplasia maligna mais freqüente entre as mulheres. Aproximadamente 49.000 novos casos de câncer de mama feminino são diagnosticados anualmente, com cerca de 10.000 óbitos. ${ }^{1}$

O s fatores de risco para o carcinoma de mama compreendem fatores internos - de predisposição hereditária ou dependente da constituição hormonal - e fatores externos - fatores ambientais, constituídos pelos agentes físico, químico e biológico capazes de causar danos ao genoma, sejam eles relacionados com o estilo de vida, à vida reprodutiva ou a outros fatores que possam favorecer 0 desenvolvimento do carcinoma. ${ }^{2}$

A história familiar da doença é, sem dúvida alguma, 0 fator epidemiológico de risco bem estabelecido. ${ }^{3}$ Entre 5 e 10\% de todos os casos de câncer de mama está relacionado à herança de mutações genéticas, tendo como característica a instalação da doença em mulheres jovens. A análise do histórico familiar revela, freqüentemente, a existência de vários outros casos da doença com características peculiares. Entre essas características podemos citar a existência de: 1- parentes afetados em três gerações sucessivas; 2- dois ou mais parentes de primeiro grau com diagnóstico da doença no período da prémenopausa; 3- casos de câncer de mama bilateral e, 4- casos de câncer de mama em homens. A ocorrência de pelo menos uma dessas características, num mesmo grupamento familial, sugere a existência de um componente genético hereditário que predispõe à doença. ${ }^{4,5} \mathrm{O}$ primeiro gene de predisposição ao câncer demama, BRCA1, foi mapeado no braço longo do cromossomo 17, a partir de análises de ligação envolvendo famílias com numerosos casos de câncer de mama, ${ }^{6}$ sendo caracterizado quatro anos mais tarde, em 1994. ${ }^{7} \mathrm{~N} 0$ ano seguinte, BRCA2, o segundo gene de susceptibilidade ao câncer de mama, foi mapeado no braço curto do cromossomo $13^{8}$ e posteriormente caracterizado. ${ }^{9}$

\section{CÂNCER HEREDITÁRIO}

A proliferação e a diferenciação celular são processos rigorosamente controlados para atender às necessidades do organismo. Q ualquer alteração nos mecanismos que regulam esses processos pode modificar a fisiologia da célula normal e, eventualmente, conduzir ao desenvolvimento de um tumor. A carcinogênese é um processo complexo, ainda pouco compreendido, que ocorre em múltiplas etapas nas quais as células se tornam maligna através de uma série de mutações progressivas e cumulativas. Tais mutações surgem a partir de lesões provocadas pela interação de agentes físicos, químicos e biológicos com o material genético. Embora as células disponham de mecanismos de reparo que removam, eficientemente, a maior parte das lesões introduzidas em seu DN A, uma pequena parcela delas não chega a ser reparada ou é reparada de forma incorreta. Como conseqüência surgem as mutações. 0 processo de transformação neoplásica se inicia quando estas mutações alteram a função de genes que regulam direta ou indiretamente a proliferação ou a sobrevida das células, como os proto-oncogenes e genes supressores de tumor. ${ }^{10}$

0 s proto-oncogenes, entre eles o c-erbB-2 (HER2), são genes que regulam positivamente a proliferação celular em resposta a estímulos fisiológicos. Algumas das mutações encontradas nestes genes resultam numa forma de proténa permanentemente ativa, de modo que a proliferação celular seja contínua e independente de estímulos externos. São, geralmente, mutações dominantes, bastando que um dos alelos esteja alterado para que o fenótipo neoplásico semanifeste. Essas formas modificadas dos proto-oncogenes são denominadas oncogenes. ${ }^{10}$

O s genes supressores de tumor, entre eles BRCA1/2 e p53, podem ser agrupados em duas categorias: a dos "gatekeepers" e a dos "caretakers". ${ }^{10} 0$ s genes gatekeepers regulam negativamente a proliferação celular ou positivamente a morte celular programada (apoptose), protegendo a célula de um crescimento desordenado. As mutações que inativam estes genes contribuem diretamente para o desenvolvimento do tumor e 0 crescimento neoplásico pode ser bloqueado pela restauração da função gatekeper perdida. Ao contrário do que se observa com os oncogenes, a presença do alelo selvagem de um gene gatekeper é suficiente para assegurar o controle da proliferação celular. Somente quando ambos os alelos são inativados é que o fenótipo transformante se manifesta. ${ }^{11,12}$ O s genes supressores de tumor da categoria caretakers suprimem indiretamente o crescimento neoplásico, codificando proteínas que atuam na manutenção da integridade do genoma. ${ }^{13,14}$

\section{EPIDEMIOLOGIA MOLECULAR}

As prevalências estimadas para portadores de mutações em BRCA1/2 são, respectivamente, $0,11 \%$ e $0,12 \%$ na população geral e entre $12,8 \%$ - 16\% em famílias de alto risco com três ou mais casos de câncer de mama ou ovário.15 Mutações germinativas nos genes BRCA1 e BRCA2 são responsáveis por, aproximadamente, $20 \%$ do 
total do risco familial observado. ${ }^{16}$ O s restantes $80 \%$ se devem a uma combinação dos efeitos produzidos por mutações em genes conhecidos de elevada penetrância como exemplo: p53, PTEN e ATM (cerca de 1\%) e alterações em genes ainda não descritos. ${ }^{17} \mathrm{U}$ ma representação esquemática da contribuição de mutações em diferentes genes para o câncer de mama familial pode ser vista na figura 1.

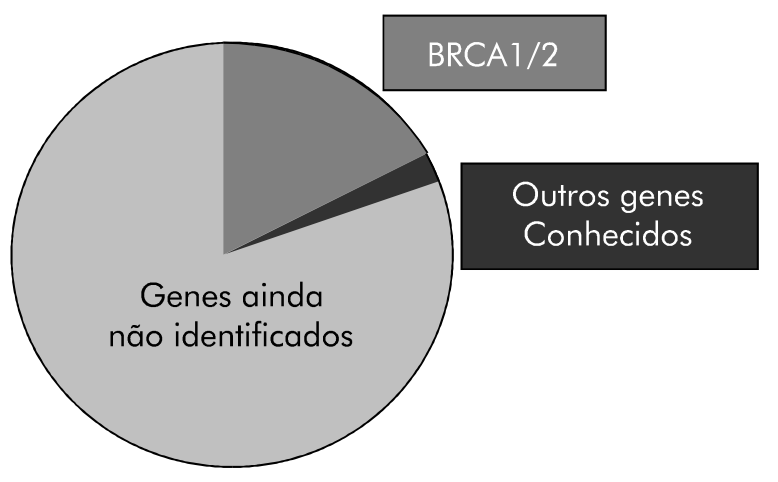

Figura 1. Contribuição genética para o câncer de mama familial.

As estimativas iniciais para 0 risco de desenvolvimento de câncer de mama ao longo da vida penetrância - em mulheres portadoras de mutações no gene BRCA1, eram superiores a $85 \% \cdot{ }^{18}$ Estudos mais recentes, no entanto, sugerem um risco de 50 a $80 \%$ para o desenvolvimento de câncer de mama até os 70 anos. ${ }^{19} \mathrm{O}$ risco para portadores de mutação em BRCA2, se aproxima daquele estimado para BRCA1, embora 0 acometimento, em idade mais avançada, seja relatado para BRCA2. ${ }^{20}$ Além do câncer de mama, portadores de mutações no gene BRCA1 também são susceptíveis ao desenvolvimento de câncer de ovário e próstata, enquanto mutações no gene BRCA2 elevam o risco para câncer de mama em indivíduos de ambos os sexos, e em outros sítios como ovário, próstata, pâncreas, estômago e vias biliares. ${ }^{21}$

0 risco para câncer de ovário em portadores de mutação em BRCA1 (aproximadamente $40 \%$ ao longo da vida) excede aquele encontrado para BRCA2 (aproximadamente $20 \%$ ao longo da vida), sendo 0 diagnóstico estabelecido em idade mais avançada nas portadoras de mutação no gene BRCA2. 0 risco para câncer de ovário não é o mesmo para todas as mutações em BRCA2. Mulheres com mutações na parte central do gene - OCCR (ovarian cancer cluster region) provavelmente possuem risco aumentado. De modo inverso, tem sido proposto que homens portadores de mutações fora da região OCCR de BRCA2 possuem risco elevado para desenvolver câncer de próstata. ${ }^{22}$

Podemos estimar a prevalência de mutações de acordo com a idade do diagnóstico de câncer de mama. Em indivíduos cujo diagnóstico se deu abaixo de 35 anos, a freqüência de mutações nos genes $B R C A 1 / 2$ varia de $5,9 \%$ a $12,9 \%$. Se esse diagnóstico ocorre entre 36-45 anos esta freqüência varia entre $2,4 \%-4,9 \%$ dos casos, aumentando para cerca de $13 \%$ quando associada a um parente de primeiro grau afetado..$^{23}$

Algumas mutações são mais prevalentes em indivíduos de grupos étnicos específicos ou geográficos. I sso se deve à presença de mutações iniciadoras nesta população, que provavelmente, surgiram há varias gerações. ${ }^{24}$ Em judias Ashkenazi (descendente da Europa Central e 0 riental) foram identificadas três mutações iniciadoras específicas: $185 \mathrm{del} A \mathrm{G}$ e 5382insC, no gene BRCA1 e 6174delT, no gene BRCA2, podendo um mesmo grupamento familiar apresentar as três mutações. Essas mutações estão presentes em $2 \%$ dessas mulheres e são responsáveis por aproximadamente $50 \%$ dos casos de câncer de mama de instalação precoce. Estima-se que $7,5 \%$ das mulheres não judias e $38 \%$ de mulheres judias com câncer de mama em idade inferior a 30 anos possuam mutações germinativas nos genes BRCA. ${ }^{25}$ $\mathrm{N}$ a I slândia, uma única mutação em BRCA2 (999del5), responde, virtualmente, por todos os casos de câncer de mama e ovário em famílias de alto risco, estando associada a câncer de mama em homens em determinadas famílias. Essa mutação foi encontrada em 0,6\% da população geral, 7,7\% das mulheres com câncer de mama e $40 \%$ dos homens com câncer de mama. ${ }^{26}$

\section{EstrutuRA EFUNČ̃O}

O s genes BRCA são estruturalmente complexos e encontram-se organizados ao longo de segmentos genômicos com aproximadamente 100kb. BRCA1 se localiza no braço longo do cromossomo 17 (17q21) e é composto por 24 exons, dos quais 22 codificam uma proteína com 1863 aminoácidos. ${ }^{7} 0$ gene BRCA2 se localiza no braço longo do cromossomo $13 q 12$ e sua estrutura é ainda mais complexa, sendo composto por 27 exons, dos quais 26 são codificantes. A proteína BRCA2 apresenta 3418 aminoácidos (figura 2). ${ }^{9}$

Os genes BRCA foram classificados como genes supressores de tumor devido à perda freqüente de heterozigosidade nos tumores desenvolvidos por indivíduos portadores de mutações nesses genes. Entretanto, nos tumores de mama de origem esporádica, mutações em ambos os genes são pouco freqüentes. A maneira pela qual a inativação dos genes BRCA conduz 
ao desenvolvimento de tumor ainda não esta completamente esclarecida. As proteínas BRCA desempenham importantes funções em diferentes processos celulares, incluindo a ativação e a regulação transcricional, o reparo de lesões no DN A, além do controle do ciclo celular, da proliferação e diferenciação celular. ${ }^{16,27}$ A função de BRCA1 e BRCA2 na recombinação homóloga e reparo do $D N A$ é sugerida por uma forte interação bioquímica de BRCA1 eBRCA2 com proténas, sabidamente, envolvidas neste processo. Além disso, múltiplas modificações ocorrem na proteína BRCA1 em resposta ao dano do DNA, incluindo um padrão de fosforilação distinto daquele que ocorre durante a transição G 1-S do ciclo celular. ${ }^{27-29}$

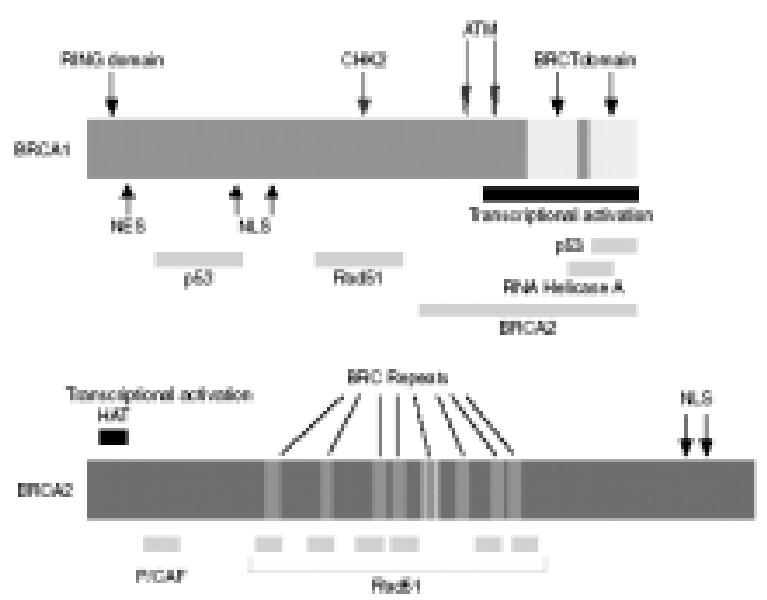

Figura 2. Esquema das proteínas BRCA e seus sítios de interação com outras proteínas (40)

A expressão de mRNA de BRCA1 e dos receptores de estrogênio estão estritamente ligados, sugerindo uma relação funcional entre os dois genes. Recentemente foi demonstrado que BRCA1 tem habilidade de regular a resposta celular aos estrogênios. Em estudos in vitro, conduzidos com células de tumores de mama, a proteína BRCA1 inibe a transcrição de genes regulados pelo receptor de estrogênio a (REa). Estes achados sugerem que, em adição à manutenção da estabilidade genômica durante períodos de rápida divisão e proliferação celular, BRCA1 possa também suprimir sinais iniciados pela ativação dos RE-a durante a puberdade e a gestação, quando a expressão de estrogênios e BRCA1 estão significativamente elevadas. A função de BRCA1 talvez seja de proteção do tecido mamário da instabilidade genética induzida pelo estrogênio através da diferenciação e reparo ao dano genético. ${ }^{30}$

A presença de um domínio RING finger no gene $B R C A 1$, queéfreqüentemente, encontrado em proteínas de regulação transcricional, sugere que BRCA1 esteja envolvido na regulação transcricional. Contudo, sabese que os domínios RING finger são encontrados em uma gran de variedade de proteínas de diferentes funções, e é indicativa da interação proteína-proteína, além da interação com D N A. ${ }^{31}$

Recentes evidências ligam as proteínas BRCA a outras supressoras de tumor - como o produto dos genes da Anemia de Fanconi (AF), que atuam no controle do ciclo celular e reparo de DN A por recombinação homóloga. A Anemia de Fanconi é uma doença genética recessiva rara caracterizada por alterações ósseas e de pigmentação de pele e alta incidência de doenças malignas hematológicas e não hematológicas. A genética desta desordem écomplexae mutações em novediferentes genes foram demonstradas. Pelo menos cinco proteínas AF formam um complexo, juntamente com BRCA1/2 e RAD 51 que atuará em resposta ao dano do D N A. ${ }^{32-34,39}$

\section{PATOLOGIA DO CÂNCER DE MAMA ASSOCIADA A MUTAÇÕES NOS GENES BRCA}

O câncer de mama hereditário possui achados clínicos distintos: a idade de acometimento é consideravelmente precoce em relação ao câncer esporádico; maior prevalência de bilateralidade; e a associação com outros tipos de tumor em famílias afetadas, como câncer de ovário e próstata. Existem fortes evidências sugerindo uma morfologia específica para tumores em portadoras de mutações nos genes BRCA. ${ }^{35}$

0 câncer de mama hereditário possui algumas diferenças biológicas interessantes quando comparado ao câncer esporádico. Em portadoras de mutações em BRCA1, uma grande proporção dos tumores é de alto grau histológico, tendem a ser aneuplóides, a apresentar altas taxas de células na fase $S$ e em mitose e infiltrado linfocitário. Este último achado é freqüente no carcinoma medular, cuja freqüência está aumentada nos carcinomas de origem hereditária. ${ }^{36}$ (Figura 3).

Figura 3. Comparação dos graus histológicos dos tumores de mama nos casos de câncer de origem esporádicos, familiar e ligado a mutações nos genes BRCA. 
0 carcinoma ductal in situ é pouco freqüente em portadoras de mutação em BRCA1, e isso se deve à rápida obliteração do componenteintraductal em virtude da alta taxa de proliferação do tumor. ${ }^{26,35} \mathrm{~A}$ expressão dos receptores hormonais (estrogênio e progesterona), pelas células neoplásicas dos carcinomas de mama, representa até hoje o único parâmetro biológico com significado preditivo e prognóstico independente. Os receptores de estrogênio ( $R E$ ) são inversamente correlacionados ao grau tumoral. Tumores de mama associados à mutação em BRCA tendem a ser de alto grau e, presumivelmente, negativo para receptor de estrogênio. A expressão do receptor de progesterona (RP) éuma evidência indireta da atividade transcricional dos $R E$, tendo forte correlação com o prognóstico, juntamente com RE. ${ }^{37,38} \mathrm{~N}$ a tabela 1 podemos observar um resumo das principais características patológicas encontrados nos casos de câncer de mama associado à mutação nos gene BRCA. ${ }^{22}$

Tabela 1. Características patológicas de BRCAl/2 associado ao câncer de mama

\begin{tabular}{l|c|c}
\hline \multicolumn{1}{c|}{ Fenótipo } & BRCA1 & BRCA2 \\
\hline Morfologia & $\begin{array}{c}\text { Ductal (sem } \\
\text { especificação) 75\%, } \\
\text { Carcinoma Medular -10\% }\end{array}$ & $\begin{array}{c}\text { Ductal (sem especificação) 75\%, } \\
\text { Carcinoma Medular }<5 \%, \\
\text { Lobular mais prevalente que } \\
\text { mulheres BRCA1 - 10\% }\end{array}$ \\
\hline $\begin{array}{l}\text { Grau } \\
\text { Histológico }\end{array}$ & Alto(grau 3-75\%) & $\begin{array}{c}\text { Médio (grau 2 - 45\%) } \\
\text { Alto (grau 3 - 45\%) }\end{array}$ \\
\hline $\begin{array}{l}\text { Receptor de } \\
\text { Estrogênio }\end{array}$ & Negativo (75\%) & Positivo (75\%) \\
\hline c-erbB-2 & Negativo (95\%) & Negativo (95\%) \\
\hline P53 & Positivo (50\%) & Positivo (40\%) \\
\hline Ciclin D1 & Negativo (90\%) & Positivo (60\%) \\
\hline $\begin{array}{l}\text { Carcinoma } \\
\text { in situ }\end{array}$ & Raro & Comum \\
\hline
\end{tabular}

A progressão dos tumores associada a BRCA1 difere daquela encontrada nos casos esporádicos em pelo menos dois pontos. Primeiro, em portadores de mutação em BRCA1 existe uma relação entre tamanho do tumor primário e número de linfonodos axilares comprometidos. Tumores maiores associados a BRCA1 são freqüentemente associados a linfonodos axilares negativos quando comparados a tumores esporádicos ou em portadoras de mutação em BRCA2. 0 pior prognóstico dos tumores relacionados a BRCA1 e linfonodo negativo ésurpreendente, uma vez quetumores sem metástases axilares são, geralmente, associados com mel hores resultados quando comparados a tumores do mesmo tamanho e linfonodo positivo. Segundo, a aparente resposta ao bloqueio estrogênico, a despeito de serem RE negativo. A ooforectomia está associada à redução de incidência de primeiro e segundo tumor primário de mama em portadores de mutação em BRCA1, e o tamoxifeno é eficaz na prevenção de um segundo tumor primário - muitas delas são RE negativo. ${ }^{22}$

\section{DISCUSSÃO}

O câncer de mama constitui-se num problema de saúde publica por ser a neoplasia maligna de maior incidência na população feminina e a primeira causa de mortalidade por neoplasia entre mulheres brasileiras.

O s riscos individuais, decorrentes da presença de antecedentes familiares com a doença, são tão marcadamente estabelecidos que a investigação de sua distribuição vem ganhando importância crescente na pesquisa do câncer de mama.

Os avanços na área da biologia molecular e da genética nas últimas décadas permitiram 0 estabelecimento de uma correlação direta entre a presença de mutações germinativas em genes de susceptibilidade e o desenvolvimento de câncer. A heterogeneidade genética do câncer de mama familiar é bem conhecida e uma parcela significativa da doença está associada à herança de mutações altamente penetrantes nos genes BRCA, cujo impacto éinfluenciado por outros fatores; como o tipo e a posição da mutação, história reprodutiva e exposição exógena a fatores carcinogenéticos. Os conhecimentos adquiridos a partir dos estudos dos genes BRCA tiveram um considerável impacto no manejo de famílias de alto risco para câncer de mama e ovário.

\section{REFERÊNCIAS}

1. Instituto $\mathrm{N}$ acional deC âncer [homepagenal nternet]. Rio de aneiro: IN CA; c1996-2005 [citado em 1 ago 2005]. Estimativas daincidênciaemortalidadepor câncer no Brasil. D isponível em: www.inca.gov.br.

2. Veronei U. M astologiaoncológica. Riodejanero: M eds; 2002.

3. H ulka BS, M oorman PG. Breast cancer: hormones and other risk factors. 2001.

4. Kerr $P, A$ shworth $A$. N ew complexities for $B R C A 1$ and BRCA2. Curr Biol. 2001;11:R668-76.

5. Rosenthal TC, Puck SM. Screening for genetic risk of breast cancer. Am Fam Phys. 1999;59(1):99-104.

6. H all JM, LeeM K, N ewman B, M orrow JE, Anderson LA, $H$ uey $B$, et al. Linkage of early-onset familial breast cancer to chromosome17q21. Science. 1990;250:1684-9.

7. Miki Y, Swensen J, Shattuck-Eidens D, Futreal PA, $\mathrm{H}$ arshman $\mathrm{K}$, Tavtigian $\mathrm{S}$, et al. A strong candidate for the 
breast and ovarian cancer susceptibility gene BRCA1. Science. 1994;266:66-71.

8. Wooster R, Bignell G, Lancaster J, Swift S, Seal S, M angion $J$, et al. I dentification of the breast cancer susceptibility geneBRCA2. N ature. 1995;378:789-92.

9. Tavtigian SV, Simard J, Rommens J, C ouch F, ShattuckEidensD, N euhausen $S$, et al. The completeBRCA2 gene and mutations in chromosome13q-linked kindreds. $\mathrm{N}$ at Genet. 1996;12:333-7.

10. M acleod K. Tumor suppressor genes. C urr O pin $\mathrm{G}$ enet Dev. 2000;10:81-93.

11. Simao TA, Ribeiro FS, Amorim LM , Albano RM , AndradaSerpa M J , C ardoso LE, et al. T P53 mutations in breast cancer tumors of patients from Rio de Janeiro, Brazil: association with risk factorsand tumor characteristics. Int J Cancer. 2002;101(1):69-73.

12. KuroseK, Gilley K, M atsumoto S, Watson PH , Zhou XP, Eng C. Frequent somatic mutations in PT EN and T P53 aremutually exclusivein thestroma of breast carcinomas. $\mathrm{N}$ at $\mathrm{G}$ enet. 2002;32(3):355-7.

13. Levitt N C, H ickson ID . Caretaker tumor suppressor genes that defend genome integrity. Trends $\mathrm{M}$ ol $\mathrm{Med}$. 202;8:179-86.

14. H oeijmakersJH. G enomemaintenancemechanisms for preventing cancer. $N$ ature. 2001;411:366-74.

15. Bouchard L, BlancquaertI, Eisinger F, FoulkesW D, Evans $\mathrm{G}$, Sobol $\mathrm{H}$, et al. Prevention and genetic testing for breast cancer: variations in medical decisions. Soc Sci Med. 2004;58:1085-96.

16. Venkitaraman AR. C ancer susceptibility and the functions of BRCA1 and BRCA2. Cell. 2002;108:171-82.

17. Ponder BAJ. C ancer genetics. N ature. 2001;411(17):336-41.

18. Ponder $M, G$ reen J. BRCA1 testing: someissuesin moving from research to service. Psycho-oncology. 1996;5:223-32.

19. Kubista M, Rosner M , M iloloza A, H ofer K, Prusa AR, Kroiss $R$, et al. BRCA 1 and differentiation. $M$ utat Res. 2002;512(2-3):165-72.

20. Bishop DT. BRCA1 and BRCA2 and breast cancer incidence: a review. Ann 0 ncol. 1999;10 Suppl 6:113-9.

21. Welcsh PL, King MC. BRCA1 and BRCA2 and the genetics of breast and ovarian cancer. $\mathrm{H}$ um $\mathrm{M}$ ol Genet. 2001;10(7):705-13.

22. N arod E, FoulkesW D. BRCA1 and BRCA2: 1994 and beyond. $N$ at Rev. 2004;4:665-76.

23. N kondjock A, G hadirian P. Epidemiology of breast cancer among BRCA mutation carriers: an overview. $C$ ancer $L$ ett. 2004;205:1-8.

24. N euhausen SL, G odwin AK, Gershoni-Baruch R, Schubert E, Garber J, Stoppa-Lyonnet D, et al. H aplotype and phenotypeanalysis of ninerecurrent BRCA2 mutations in 111 families: results of an international study. Am J H um Genet. 1998;62:1381-8.

25. Sakorafas GH , Tsiotou AG . G enetic predisposition to breast cancer: a surgical perspective. Br J Surg. 2000;87(2):149-62.

26. Iau PTC, M acmillan RD, Blamey RW. G ermlinemutations associated with breast cancer susceptibility. Eur J $C$ ancer. 2001;37:300-21.

27. Welcsh $P L, O$ wens $K N$, King $M C$. Insights into the functions of BRCA1 and BRCA2. Trends $G$ enet. 2000;16(2):69-74.

28. D eng CX, BrodieS. Roles of BRCA 1 and its interacting proteins. Bioessays. 2000;22:728-37.

29. D eng CX, Scott]. Roleof tumor supressor geneBRCA 1 in stability and mammary gland tumor formation. 0 ncogene. 2000;19:1059-64.

30. $\mathrm{H}$ ilakivi-ClarkeL. Estrogens, BRCA1 and breast cancer. C ancer Res. 2000;60:4993-5001.

31. BertwistleD , Ashworth A. Thepathology of familial breast cancer. $\mathrm{H}$ ow do the functions of $B R C A 1$ and $B R C A 2$ relate to breast tumour pathology? Breast Cancer Res. 1999;1(1):41-7.

32. Fei $P, Y$ in J, Wang W. N ew advancesin the D N A damage responsenetwork of Fanconi anemia and BRCA proteins. Cell Cycle. 2005;4(1):80-6.

33. Turner $N$, Tutt A, Ashworth A. Targeting the D N A repair defect of BRCA tumours. Curr O pin Pharmacol. 2005;5:388-93.

34. Venkitaraman AR. Tracing thenetwork connecting BRCA and Fanconi anaemia proteins. N at Rev. 2004;4:266-76.

35. Blackwood MA, Weber B. BRCA1 and BRCA2: from molecular genetics to clinical medicine. J Clin O ncol. 1998;16(5):1969-77.

36. $\mathrm{O}$ Isson $\mathrm{H}$. A hypothesis about tumour development and the clinical features of hereditary breast cancer. EurJ Cancer. 2001;37:2023-9.

37. H emmink K, G ranström C. M orphological types of breast cancer in family members and multiple primary tumours: ismorphological genetically determined? B reast $C$ ancer $R e$. 2002;4(R 7):1-6.

38. 0 sin PP, Lakhani SR. Thepathology of familial breast cancer: immunohistochemistry and molecular analysis. Breast Cancer Res. 1999;1(1):36-40.

39. Balmain A, Gray J, Ponder B. Thegenetics and genomics of cancer. $N$ at G enet. 2003;33 Suppl:238-44.

40. YoshidaK, M iki Y. Roleof BRCA1 and BRCA2 as regulators of $D N A$ repair, transcription, and cell cyclein responseto D N A damage. Cancer Sci. 2004;91(11):866-71. 